\title{
Ongoing Climate Change in the Arctic
}

\author{
John E. Walsh, James E. Overland, \\ Pavel Y. Groisman, Bruno Rudolf
}

\begin{abstract}
During the past decade, the Arctic has experienced its highest temperatures of the instrumental record, even exceeding the warmth of the 1930s and 1940s. Recent paleo-reconstructions also show that recent Arctic summer temperatures are higher than at any time in the past 2000 years. The geographical distribution of the recent warming points strongly to an influence of sea ice reduction. The spatial pattern of the near-surface warming also shows the signature of the Pacific Decadal Oscillation in the Pacific sector as well as the influence of a dipole-like circulation pattern in the Atlantic sector. Areally averaged Arctic precipitation over the land areas north of $55^{\circ} \mathrm{N}$ shows large year-to-year variability, superimposed on an increase of about $5 \%$ since 1950 . The years since 2000 have been wetter than average according to both precipitation and river discharge data. There are indications of increased cloudiness over the Arctic, especially low clouds during the warm season, consistent with a longer summer and a reduction of summer sea ice. Storm events and extreme high temperature show signs of increases. The Arctic Ocean has experienced enhanced oceanic heat inflows from both the North Atlantic and the North Pacific. The Pacific inflows evidently played a role in the retreat of sea ice in the Pacific sector of the Arctic Ocean, while the Atlantic water heat influx has been characterized by increasingly warm pulses. Recent shipboard observations show increased ocean heat storage in newly sea-ice-free ocean areas, with increased influence on autumn atmospheric temperature and wind fields.
\end{abstract}

Electronic supplementary material The online version of this article (doi:10.1007/s13280-011-0211-z) contains supplementary material, which is available to authorized users.
Keywords Arctic climate - Climate change . Arctic temperature $\cdot$ Precipitation $\cdot$ Arctic Ocean changes

\section{INTRODUCTION}

The cryospheric changes described in Callaghan et al. (2011a [this issue]) and AMAP (2011) on which it is based are part of a broader suite of interrelated variations in the Arctic climate system. A thorough review of Arctic climate, its relation to external forcing, and its variations through 2004 is presented in Chap. 2 of the Arctic Climate Impact Assessment (ACIA 2005). Accordingly, we preface both the AMAP (2011) SWIPA chapters and the Callaghan et al. (2011a [this issue]) papers with a brief overview of more recent Arctic climate variations, updating the ACIA climate chapter by summarizing new findings that have emerged in the post-2004 period. This article will emphasize the primary climate drivers (temperature, precipitation, storminess, clouds, and the ocean) of cryospheric change. A section on each variable contains a review of the recent literature (as well as additional results for temperature and precipitation). Recent changes of the primary cryospheric variables (snow, sea ice, glaciers, and permafrost) are presented in other articles in Callaghan et al. (2011a [this issue]) and the AMAP (2011) SWIPA report on which it is based.

\section{ARCTIC TEMPERATURES}

Section 2.7 of the Arctic Climate Impact Assessment (ACIA 2005) reviews Arctic climatic history from the prequaternary through the Holocene. Since the publication of the 2005 assessment, studies have refined temporal and 
regional variations of Arctic paleoclimate. An integrative study, published recently by Kaufman et al. (2009), provides a reconstruction of pan-Arctic summer temperatures over the past 2000 years, based on various proxies including lake sediments, pollen records, diatoms, and tree rings. Figure 1 show this reconstruction, which adds to our previous knowledge base by showing that the Arctic had been undergoing a slow (summer) cooling for most of the 2000 -year period before the 1800s. This cooling is consistent with the slow variations of the earth-sun orbital parameters, which affect the solar radiation reaching the Arctic in the sunlit portion of the year. However, the recent warming since the 1800 s, as shown by the instrumental data (red line in Fig. 1), has left the Arctic warmer than at any time in the preceding 2000 years by a considerable margin. The recent instrumental temperatures are outside the envelope of the natural variability depicted by the reconstruction; for example, the warming is far more than simply a recovery from the so-called Little Ice Age, which is apparent from the 1500s through the 1800s in Fig. 1. While Fig. 1 conveys a visually striking picture of recent Arctic warming, it should be noted that the data used by Kaufman et al. (2009) were biased toward Greenland, with very few sites in Siberia and no data from the polar ocean. In addition, the locations of the proxy sites generally do not correspond with the instrumental data locations, thus contributing to the differences between the proxy and instrumental values in the mid-twentieth century in Fig. 1. It is also noteworthy that, when uncertainties from the methods and the sparseness of the data are included, the recent decades of proxy data (blue line in Fig. 1) are not significantly warmer than 2000 years ago.
The recent warming is highlighted in greater temporal detail in Fig. 2, which shows the annual temperatures averaged over a pan-Arctic domain, $60-90^{\circ} \mathrm{N}$, updated through 2009. Consistent with the reconstruction in Fig. 1 and with the Arctic temperature depictions in the Arctic Climate Impact Assessment, Fig. 2 shows the early twentieth century warming followed by the mid-century cooling and the late-century warming. Whether intrinsic variability or another form of natural or anthropogenic forcing was a leading factor in the emergence of the early twentieth century warming is still debated (Wood and Overland 2009). Notable for this study, however, is the fact that the warmest 5 years in the entire record have occurred in the post-ACIA period (2005 onward). Monte Carlo tests (1000 trials in which the data points in Fig. 2 are randomly reordered) show that the likelihood of such a sequence occurring by random chance is near zero. The inclusion of the past 5 years takes the recent Arctic warming from a state of temperatures comparable to the 1930s to a state that is warmer than then. This represents one of the more notable Arctic climate occurrences of the post-ACIA period. It is consistent with the reductions of sea ice, snow cover, and glacier mass discussed in Callaghan et al. (2011a [this issue]).

The recent Arctic warming varies with season and is stronger than the warming in middle and lower latitudes (Fig. 3). It is also stronger than the warming over Antarctica in all calendar months except Aug-Sep, when the warming near both Poles is comparable. Of particular note is the seasonality of the Arctic warming, which is greatest over the Arctic Ocean during autumn and early winter. This seasonality is consistent with the recent loss of Arctic

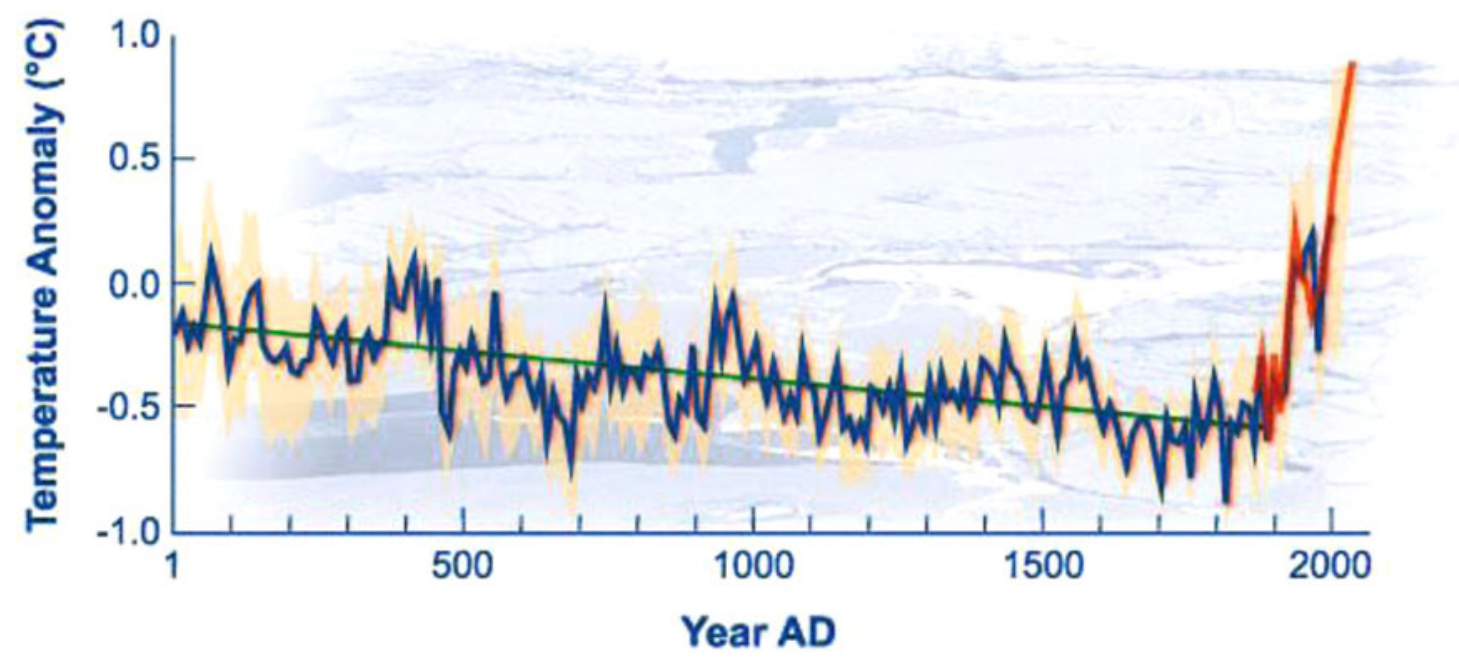

Fig. 1 The long-term cooling trend in the Arctic was reversed during recent decades. The blue line shows the estimated Arctic average summer temperature anomaly (relative to the mean for 1961-1990) over the last 2000 years, based on proxy records from lake sediments, ice cores, and tree rings. The pink shaded area represents variability among the 23 sites used for the reconstruction. The green line shows the long-term cooling trend. The red line shows the recent warming based on instrumental temperatures. From Kaufman et al. (2009), modified by UCAR 
Fig. 2 Annual Arctic temperature anomalies $\left({ }^{\circ} \mathrm{C}\right)$ for 1880-2009, averaged over $60^{\circ}-90^{\circ} \mathrm{N}$, relative to the mean for 1961-1990. Based on station observations of surface air ( $2 \mathrm{~m}$ ) temperatures only. From Groisman, NOAA/National Climate Data Center

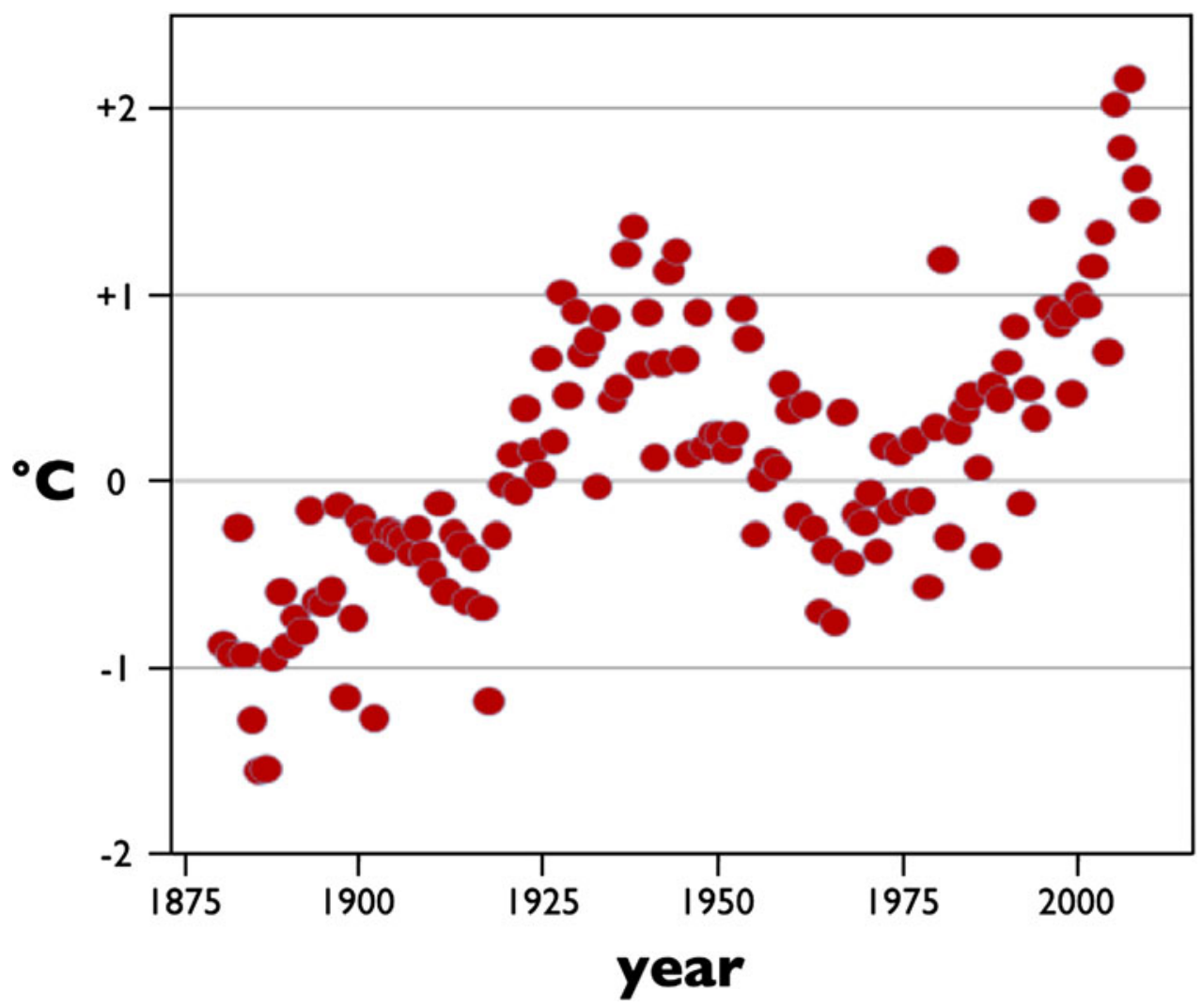

sea ice, and it serves as an indication that the ice-albedo and ice insulation feedbacks have emerged as contributors to temperature anomalies in the Arctic. The ice insulation feedback refers to additional ocean heat storage in recent sea-ice-free areas. A secondary maximum of Arctic warming propagating poleward from 50 to $60^{\circ} \mathrm{N}$ during spring is consistent with an earlier seasonal loss of snow cover over northern land areas, as discussed in Callaghan et al. $(2011 \mathrm{~b}, \mathrm{c})$. The seasonal variation of the warming is also consistent with greenhouse-driven changes projected by global climate models (ACIA 2005).

The role of the sea ice feedbacks in the Arctic temperatures of the past 5 years is further supported by the Online Supplementary Material, Figs. A and B which show the spatial patterns of the annual and seasonal temperature anomalies of the past 5 years relative to the mean temperatures for 1951-2000. In contrast to the Arctic warming in the 1930s, which was centered in the Atlantic Arctic, recent temperature increases are Arctic-wide. The annual pattern in Fig. A contains anomalies exceeding $2^{\circ} \mathrm{C}$ over much of the Arctic Ocean, and it shows a very apparent polar amplification. It should be noted that reduced ice concentrations and thicknesses, in addition to reduced ice extent, can contribute to the feedback between sea ice and temperature over the central Arctic Ocean. Equatorward of the Arctic Ocean, the warming is generally stronger over the continents than over the oceans. These spatial features are also consistent with greenhouse-driven projections of change simulated by climate models.

The seasonal patterns in the Online Supplementary Material (Fig. B) highlight the maximum warming in autumn and winter, as noted in the latitude-season depiction in Fig. 3. The seasonal patterns, especially for winter, contain more spatial variability, consistent with advective influences arising from anomalies of the atmospheric circulation. Differences in the seasonal patterns relative to the corresponding patterns in ACIA (2005) include the warming maxima over the marginal ice zone during autumn and winter, as well as some warming over the Arctic Ocean during summer-despite the large thermal capacity of the ocean. The summertime warming of the Arctic Ocean is consistent with thinner sea ice and/or an earlier retreat of sea ice during summer, as documented in Meier et al. (2011).

To some extent, these recent spatial patterns of the temperature change are shaped by the phase of low-frequency (decadal or multidecadal) variations of the atmospheric circulation. Two large-scale modes for which there are documented effects on regional Arctic air temperatures are (1) the Arctic Oscillation, which drives temperature anomalies from eastern Canada across the North Atlantic to northern Eurasia (Thompson and Wallace 2000) and (2) the Pacific Decadal Oscillation (PDO), which has a strong influence on sub-arctic temperatures in the Pacific sector 


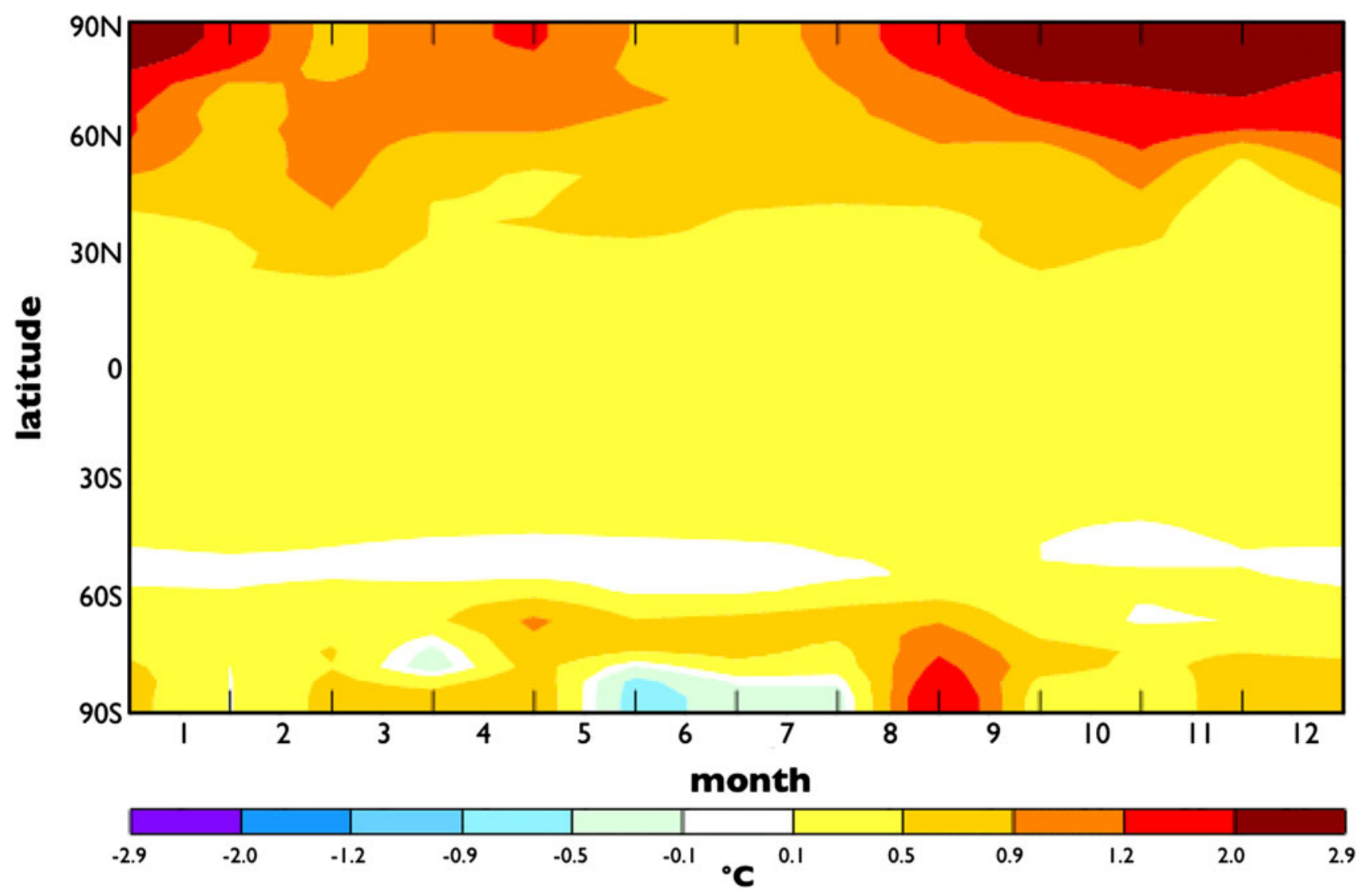

Fig. 3 Temperature anomalies averaged over 2001-2009 (relative to the mean for 1951-2000) shown as function of calendar month $(x$ axis, 1 Jan, $12 \mathrm{Dec})$ and latitude $\left(y\right.$-axis, ${ }^{\circ} \mathrm{N}$ or $\left.{ }^{\circ} \mathrm{S}\right)$. From NASA Goddard Institute for Space Studies, based on station temperature

(Mantua and Hare 2002). The Arctic warming of the late 1980s and early 1990s has been attributed (e.g., Comiso 2003; Overland et al. 2008) to a predominantly positive phase of the Arctic Oscillation (Online supplementary material, Fig. C). The warming of the 1980s-1990s was indeed stronger over northern Eurasia than over many other sectors of the Arctic. In contrast, the more recent Arctic warming cannot be attributed to the Arctic Oscillation. First, the Arctic Oscillation has been in a generally neutral state, oscillating between positive and negative phases, since 1997-yet the Arctic's warmest years in the instrumental record have occurred since 2004 (Fig. 2). Second, the Arctic Oscillation Index reached the most negative values ever recorded in Dec 2009-Jan 2010. At the same time, the high Arctic was relatively warm while northern Europe and Asia suffered from extreme cold. These concurrent anomalies of opposite sign point to the perils of using spatially aggregated temperatures as proxies for temperatures in particular sub-regions.

The PDO has been shown to be a primary determinant of wintertime temperature anomalies in northwestern North America (Hartmann and Wendler 2005). The PDO index measurements and Hadley/Reynolds sea surface temperatures (http://data.giss.nasa.gov/gistemp/seas_cycle.html). The scale for temperature anomalies $\left({ }^{\circ} \mathrm{C}\right)$ is provided below the color bar

(evaluated from Pacific sea surface temperatures) indeed has a multidecadal character. The increase of the PDO index from the middle 1970s to the early 1980s corresponds with a substantial increase in temperatures over Alaska and northwestern Canada. The negative PDO index of 2008-2009 coincides with an episode of below-normal temperatures in 2008-2009. The influence of the PDO extends westward to far eastern Siberia, where temperature anomalies are out of phase with those of Alaska and the Yukon, largely as a result of the intensification cycles of the Aleutian low pressure system in conjunction with the PDO. Indeed, the couplet of temperature anomalies of opposite sign in the winter pattern of Fig. B (Online Supplementary Material) and also in the multidecadal trends shown in the Arctic Climate Impact Assessment's Sect. 2.6.2.1 (ACIA 2005), are driven, to a large extent, by the PDO and associated wind anomalies in the vicinity of the Aleutian low. A major challenge in anticipation of temperature changes in the Pacific Sub-arctic is related to our inability to predict phase transitions of the PDO. For purposes of our concluding discussion (Conclusion), however, we note that neither the PDO nor the Arctic 
Oscillation, the two major modes of northern hemispheric low-frequency climate variability, has been in a phase conducive to Arctic warming during the last several years-despite the anomalous pan-Arctic warmth of these years (Fig. 2).

The relatively high Arctic temperatures of recent years have also been associated with atmospheric circulation patterns conducive to the export of older, thicker sea ice from the Arctic Ocean to the North Atlantic. Several postACIA studies have pointed to the prominent role of similar circulation patterns, which have been assigned names ranging from the Dipole Anomaly (Wu et al. 2006) to the Arctic Rapid-Change pattern (Zhang et al. 2008). Current consensus is to refer to this newly dominant atmospheric circulation pattern as the "Arctic Dipole (AD)". These patterns are best developed in the winter half of the year but can affect sea ice export in all seasons, and they are argued to have preconditioned the Arctic sea ice cover for the rapid summer retreat of the late 2000s (Smedsrud et al. 2008). Overland and Wang (2005) and Overland et al. (2008) highlight the meridional (across-pole) character of this atmospheric pattern which, in addition to affecting sea ice export, advects warmth into the Arctic Ocean in a pattern distinct from the PDO and the Arctic Oscillation.

Recently, Overland and Wang (2010) have presented evidence that the loss of sea ice and additional ocean heat storage (Jackson et al. 2010) have become sufficient to influence the atmospheric heat budget and circulation pattern in the autumn and early winter months. Honda et al. (2009) predicted this sea ice-atmospheric circulation connectivity from modeling studies, and Francis et al. (2009) arrive at a similar conclusions based on a data analysis encompassing a larger sample of years.

A major topic of attention in the past few years has been the vertical structure of the recent Arctic warming, since the vertical structure provides clues to the nature (drivers) of the warming. Graversen et al. (2008) argued that an elevated maximum of the warming precludes a major role of surface heating, although several subsequent studies (Grant et al. 2008; Bitz and Fu 2008; Alexeev et al. 2009) have provided evidence of a surface-based warming. The apparent discrepancy between the different analyses is due to the use of different datasets (reanalyses) and time periods. As shown in the Online Supplementary Material (Fig. D), latitude-height cross-sections depict a warming that is clearly strongest at the surface during autumn in the NCEP/NCAR reanalysis. The European ERA-40 database used by Graversen et al. (2008) does not show the nearsurface warming seen in the NCEP/NCAR reanalysis. Moreover, the data on which the cross-section in Fig. D is based include the years of extreme ice minima that were not in the Graversen et al.'s study, giving credence to the argument that the ice-albedo feedback to Arctic temperatures is just now emerging in the post-ACIA period (Serreze et al. 2008).

Finally, the studies of variations and trends of Arctic temperatures have focused almost exclusively on monthly, seasonal, or annual mean temperatures. There has been little work on systematic changes in variability or extremes. Among the few studies of this kind, Walsh et al. (2005) found little evidence of increased variance of daily temperatures in Alaska and western Canada over the 50 years ending in 2000. However, there were indications of an increased frequency of daily extreme temperatures from the 1950 s to the 1990 s. Whether this trend has continued into the past 5 years of record Arctic warmth (Fig. 2) is unknown. On a more local scale, Weatherhead et al. (2010) report a decrease of the persistence of daily springtime temperatures at Baker Lake, Canada. This decrease of persistence corresponds with reports from indigenous residents that their weather has become less predictable. Model projections do indicate increasing frequencies of record high daily temperatures in twenty-first century scenario simulations (Timlin and Walsh 2007). Given the impacts of extreme events on other parts of the cryosphere and on humans and ecosystems, a priority for research is a determination of the relationship between changes in means and extremes of Arctic climate variables.

\section{ARCTIC PRECIPITATION}

Evidence for trends of Arctic precipitation is complicated by inadequacies in both in situ measurements and remotesensing-derived estimates of precipitation in cold climates. While these deficiencies were highlighted in ACIA (2005) and in the SWIPA report (AMAP 2011), we reiterate here the challenges created by changing station distributions and gauge undercatch. Both these factors impede attempts to construct temporally homogeneous records of areally averaged precipitation. Partly for this reason, variations of Arctic precipitation have been examined using atmospheric reanalysis output, either as directly simulated by the reanalysis models of the European Center for Mediumrange Weather Forecasts and the US National Centers for Environmental Prediction (Serreze et al. 2005) or as moisture flux convergences (e.g., Peterson et al. 2006).

The most comprehensive collection if in situ precipitation data is that of the Global Precipitation Climatology Center (GPCC), which has produced Arctic precipitation time series such as Fig. 4's depiction of yearly precipitation averaged over the land areas north of $55^{\circ} \mathrm{N}$ for hydrologic winter (Oct-March) and hydrologic summer (Apr-Sep). The data show considerably greater precipitation in the warm season than in the cold season, considerable interannual variability, and a small increase of about 
$5 \%$ over the period 1951-2009, based on a polynomial fit to the data. The increase in Fig. 4 is rather modest in relation to the variability and is not statistically significant, pointing to the difficulty of extracting significant signals from highly variable precipitation data. However, for the period 1951-2009, the five wettest years (in excess of $450 \mathrm{~mm}$ ) have all occurred in the most recent decade: 2000, 2002, 2005, 2007, and 2008. Anomalies in both hydrologic winter and hydrologic summer have contributed to these large amounts in the recent years. As noted in Overland et al. (2011), global climate models project an increase of Arctic precipitation under all scenarios of greenhouse forcing. Nevertheless, in the models as in the observational data, interannual variability is large.

The increasing frequency of wet years in high latitudes is supported by increases in river discharge amounts, which are shown in the Online Supplementary Material (Fig. E). For Eurasia, the discharge of the largest rivers has increased by about $10 \%$ since 1935, despite the large interannual variations that are apparent (Peterson et al. 2002). The rate of increase for North America is similar, although the record length of river discharge is shorter for North America. The discharge curves for the two continents show a positive correlation, and their extreme years also show some correspondence with the annual precipitation amounts in Fig. E.

\section{STORMINESS}

In addition to their highly publicized impacts on coastal regions and their residents, storms impact other components of the cryosphere through their associated precipitation (affecting glaciers, ice sheets, snow cover and even permafrost), winds (affecting sea ice motion and the distribution of snow on land and sea ice), and waves (affecting coastal permafrost). While storms have received increased diagnostic analyses through case studies (e.g., Roberts et al. 2008), there have been few rigorous evaluations of variations and trends of storminess in the Arctic, particularly the central Arctic. Wang et al. (2006) reported a northward shift of cyclone activity, primarily during winter, over Canada during 1953-2002, while Mesquita et al. (2010) found that temporal trends of cyclones in the North Pacific have generally been weak over the 60 -year period ending 2008, although the US Global Change Research Program (Karl et al. 2009) points to increased impacts of storms on the northern Alaskan coast. Since, any increases of coastal flooding and erosion are also related to retreating sea ice, the role of storminess per se can be difficult to unravel. Nevertheless, it is apparent from the absence of a comprehensive (pan-Arctic) evaluation of recent variations in storminess that there is a need for systematic assessments of storminess in the Arctic. Such assessments should

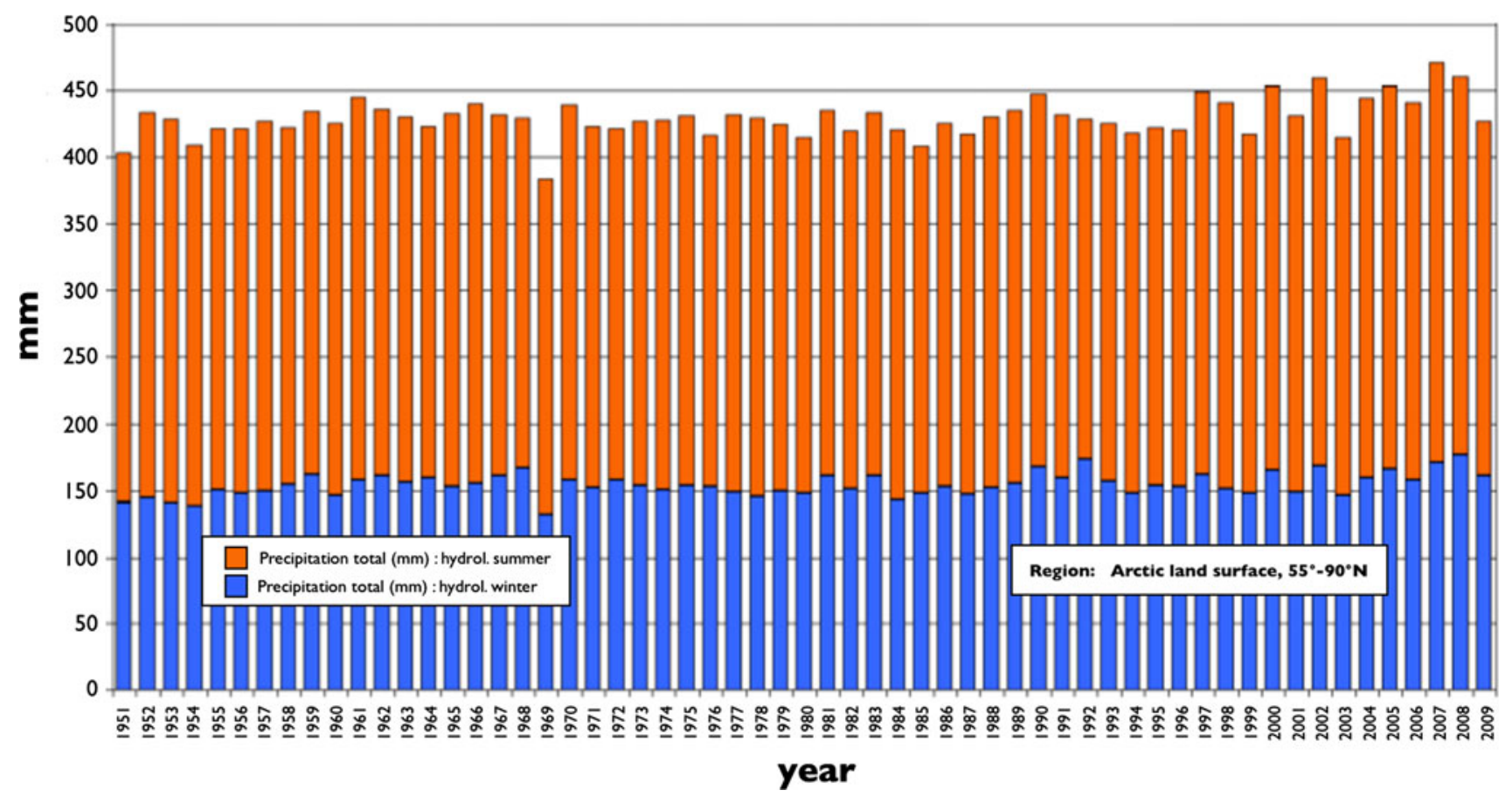

Fig. 4 Annual precipitation (mm) for 1951-2009 based on station data averaged over land areas north of $55^{\circ} \mathrm{N}$ for the hydrologic winter (lower, blue) and hydrologic summer (upper, orange). From Global

Precipitation Climatology Center/WMO/Deutscher Wetterdienst (Courtesy B. Rudolf) 
include both historical variations and their diagnosis, together with more substantive attempts to project changes into the future.

\section{CLOUDINESS}

Through their large contributions to the surface energy budget, Arctic clouds can have important impacts on the surface energy budget and the cryosphere. These impacts can be manifested in interannual variations as well as trends. For example, Kay et al. (2008) show that the extreme retreat of sea ice in the summer of 2007 was accompanied by unusually clear skies over much of the Arctic Ocean. Trends and other longer-term variations have been addressed in several post-ACIA studies, although one must be cognizant of the observational challenges posed by Arctic clouds, both for remote sensing and for in situ measurements.

Wang and Key (2005) used Advanced Very High Resolution Radiometer (AVHRR) infrared satellite imagery to compute trends of $-6,+3,+2$, and $-2 \%$ per decade during 1982-1999 for winter, spring, summer, and autumn, respectively. Eastman and Warren (2010), on the other hand, used surface-based observations from 1991 to 2007 to obtain small positive trends in all seasons. Low clouds were primarily responsible for these trends. Perhaps more importantly for cryospheric changes, clouds over sea ice showed a tendency to increase with warming temperatures and decreasing sea ice in all seasons except summer. Particularly in autumn, there was a positive low-cloud response to reduced sea ice, indicating that recent cloud changes may be enhancing the warming of the Arctic and accelerating the decline of sea ice (Eastman and Warren 2010). This suggestion is consistent with the recent modelbased results of Vavrus et al. (2010), who found that, in ensembles of twenty-first century projections by the Community Climate System Model (CCSM3), clouds increased in autumn and decreased in summer during periods of rapid sea ice loss. This seasonality of the sea ice/ cloud associations is not inconsistent with the loss of sea ice in recent years such as 2007, and it could amplify the loss of sea ice in the future.

\section{OCEAN TEMPERATURE VARIATIONS}

A key driver of cryospheric change is the temperature variability of the high-latitude oceans. For example, the heat content of the polar oceans directly affects sea ice, tidewater glaciers and ice shelves, snowfall over the high latitudes, and perhaps even the large-scale atmospheric circulation. Salinity variations affect the stratification and control the locations of deep mixing of the oceans, while high-latitude ocean currents contribute to the driving of sea ice motion and the advection of heat and freshwater anomalies. Historically the high-latitude oceans have been woefully undersampled by observations, especially below the surface. However, during the past decade, and especially in the post-ACIA period of the International Polar Year (IPY, 2007-2009), there have been unprecedented opportunities to monitor the Arctic Ocean and its exchanges with middle latitudes-precisely during a period of unprecedented change in the cryosphere.

Insights into high-latitude ocean variability, as gleaned from preliminary analyses of IPY-period observational data, have been summarized by Dickson and Farhbach (2010). We briefly summarize here those insights that have potential implications for cryospheric variations documented elsewhere in this issue. First, the annual mean northward transport through the Bering Strait in 2007 was comparable (about $1 \mathrm{~Sv}$ ) to the previous highest annual value. Since, there were also positive anomalies of heat content, it appears that "the Bering Strait heat flux in 2007 was also at a record-length high" (Dickson and Farhbach 2010 , p. 5). In recent years, a more immediate driver of sea ice melt appears to be associated with a near-surface temperature maximum (NSTM) at a depth of $\sim 25 \mathrm{~m}$ in the Canada Basin, where the NSTM may serve to maintain thinner ice during winter, an earlier melt during spring, and hence year-to-year persistence of ice anomalies (Jackson et al. 2010). The somewhat deeper $(\sim 60 \mathrm{~m})$ layer of Pacific Summer Water (black arrows in Fig. F, Online Supplementary Material) may also have played a role in the summer ice retreat. Thinner ice in this region could also favor the wind-stress/ice-loss feedback mechanism proposed by Shimada et al. (2006). Second, North Atlantic inflows appear to be increasingly consequential for the Arctic Ocean. North Atlantic inflows to the Arctic through the Barents Sea appear to have reached their highest temperatures in 100 years (Holliday et al. 2007). In addition, mooring measurements from the Arctic Ocean indicate the propagation of increasingly warm water in a cyclonic direction around the Arctic Ocean shelf break (Fig. 5), consistent with the mean pattern of Arctic Ocean currents (Online Supplementary Material, Fig. F). Because the Atlantic layer containing this anomalous heat is subducted several $100 \mathrm{~m}$ below the surface as it circulates through the Arctic Ocean, the role of its anomalous heat in the sea ice retreat and other cryospheric variations has not been firmly established. The Atlantic water heat influx to the Arctic Ocean appears to be characterized by increasingly warm pulses separated by brief respites (Polyakov et al. 2011). As shown in Fig. 5, one such respite of cooling appears to have occurred in 2008-2009, although the Fram Strait cross-sections show that the next pulse of warming may 


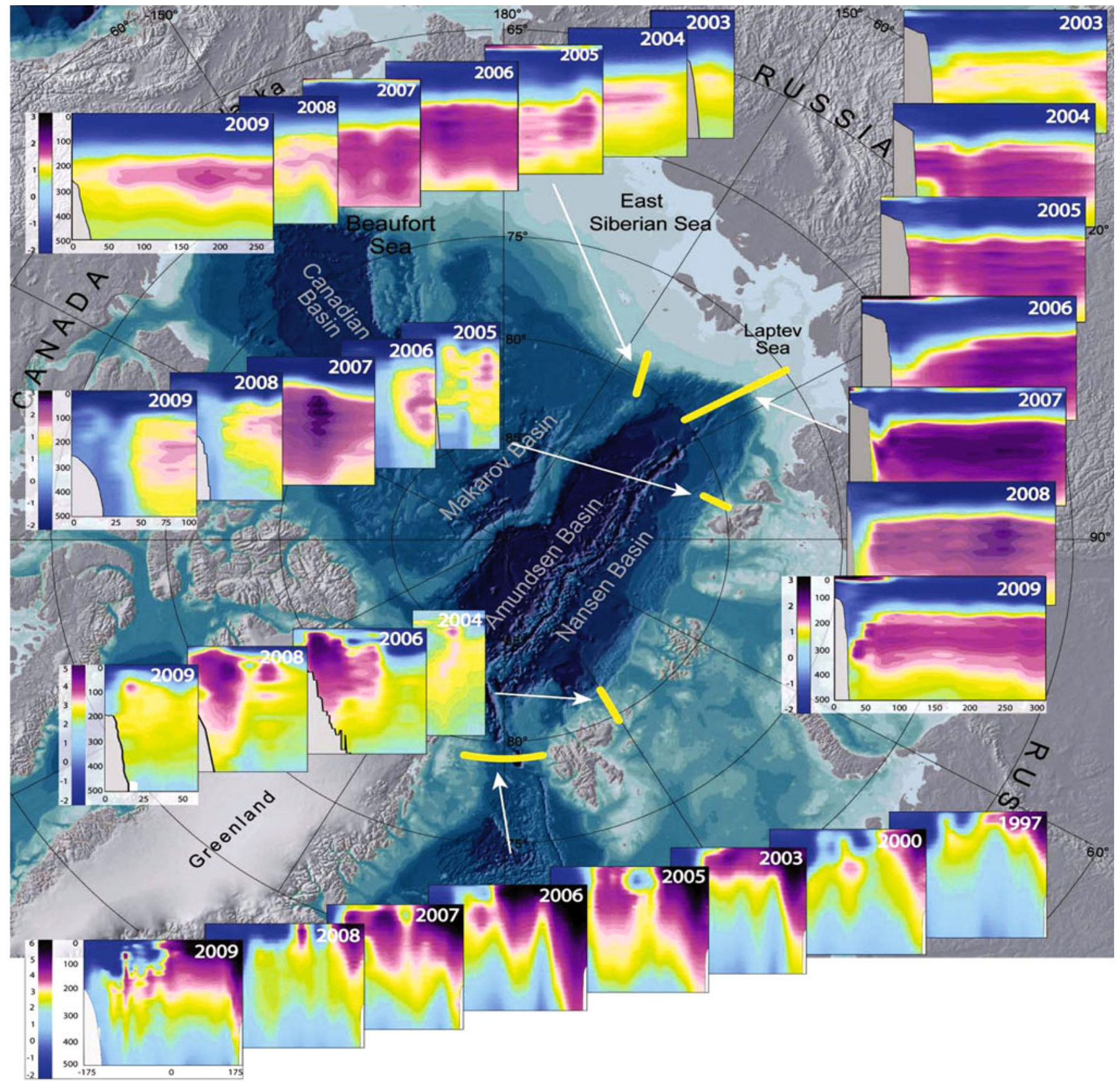

Fig. 5 Cross-sections of temperature in the upper layers of the Arctic Ocean. Years are indicated in the upper right of each panel. The temperature scale is shown in color bars at the left of each sequence.
Depths are in meters and horizontal distances along transects are in kilometers. From I. Polyakov, International Arctic Research Center and Polyakov et al. (2011) now be on the doorstep of the Arctic Ocean. Finally, IPY measurements in various straits of northern Canada have confirmed the importance of the Canadian Archipelago for the freshwater flux from the Arctic Ocean to the North Atlantic, providing significant inputs to the Meridional Overturning Circulation and thus to climate (Dickson and Farhbach 2010). The nature of the linkage between Arctic Ocean outflows and climate remains a holy grail of Arctic research.

\section{CONCLUSION}

The preceding review of recent Arctic climate variations, with an emphasis on temperature and precipitation, serves two purposes. First, Arctic temperature and precipitation variations are key drivers of recent Arctic cryospheric change. Taken together with the cryospheric changes presented in Callaghan et al. (2011a) a picture emerges of Arctic changes that are generally consistent, in fact 
interconnected, across the Arctic system. Second, the preceding summary shows that Arctic climate has entered a unique period relative to the instrumental record and, in the case of summer temperatures, relative to 2000-year reconstructions of past variations. The unprecedented warmth of the past 5 years reinforces the urgency of an ongoing assessment of combined cryospheric/atmospheric/ oceanic changes in the North. From a general climate perspective, the results point to the emergence of the icealbedo and ice-insulation feedbacks in the seasonal and spatial patterns of the recent temperature anomalies in the Arctic. This emergence is the most fundamentally important development in high-latitude climate since the publication of the Arctic Climate Impact Assessment in 2005, because these processes promote further Arctic amplification and increase the potential for connectivity between the Arctic and mid-latitudes. Given the absence of strong anomalies of large-scale circulation drivers such as the Arctic Oscillation and the PDO in the past 5 years, the recent events support the changes anticipated in ACIA (2005), and this echoes the statement of Serreze and Francis (2006, p. 241) that "Given the general consistency (of ongoing changes) with model projections, we are likely near the threshold when absorption of solar radiation during summer limits ice growth the following autumn and winter, initiating a feedback leading to a substantial increase in Arctic Ocean surface air temperatures". The cryospheric and atmospheric changes of the past 5 years indicate that we may well have crossed this threshold.

The results presented here also point to observational needs that are discussed in more detail in Key et al. (2011). There is a major lack of mid-tropospheric data over the Arctic to support the quality of atmospheric reanalysis products from major climate centers. These reanalysis products, in turn, are the basis for understanding ongoing Arctic climate changes. In addition, the precipitation estimates summarized in "Arctic Precipitation" are, by necessity, for Arctic land areas only. There are no systematically compiled sources of precipitation over the Arctic Ocean and its marginal seas, although it should be noted that Peterson et al. (2006) deduced recent increases of precipitation over the sub-arctic North Atlantic on the basis of computed moisture flux convergences in atmospheric reanalyses. Moreover, the station-derived estimates of precipitation for land areas in the Arctic have uncertainties arising from measurement errors (gauge undercatch of snow, for which only approximate correction procedures exist) and from the preferential siting of precipitation gauges in low-elevation areas. Even temperatures over the Arctic Ocean are subjected to uncertainties, as the estimates of surface air temperatures over ice-covered seas are generally based on extrapolation of temperature anomalies from nearby land areas. Satellite-derived estimates of
Arctic surface (skin) temperatures are generally biased toward cloud-free conditions.

Despite the uncertainties in variables such as Arctic cloudiness and precipitation, the trends in other parts of the Arctic climate system are the largest observed in the historical record, and even over the past 2000 years. Moreover, these changes are consistent with the trends projected by global climate models as described in the modeling chapter of the AMAP (2011) SWIPA report. While natural variations may result in interannual to decadal-scale deviations from the recent trends, the trends described here should continue and should dominate Arctic environmental change by the later decades of the twenty-first century.

Acknowledgments This paper benefitted from helpful comments and editorial assistance from Margareta Johansson, Terry Callaghan and Terry Prowse. The authors also acknowledge valuable scientific input provided by the contributing and lead author teams of the Snow, Water, Ice and Permafrost in the Arctic (SWIPA) assessment report. The Secretariat of the Arctic Monitoring and Assessment Programme provided the logistical support that enabled the SWIPA activity to come to fruition.

\section{REFERENCES}

ACIA. 2005. Arctic climate impact assessment. 1042 pp. Cambridge: Cambridge University Press.

AMAP. 2011. Snow, water, ice and permafrost in the Arctic (SWIPA). Arctic Monitoring and Assessment Programme (AMAP), Oslo.

Alexeev, V.A., I. Esau, I.V. Polyakov, S. Byam, and S. Sorokina. 2009. Vertical structure of recent Arctic warming from observed data reanalysis products. Climatic Change 34: 437-439.

Bitz, C.M., and Q. Fu. 2008. Arctic warming aloft is data set dependent. Nature 455: E3-E4. doi:10.1038/nature07258.

Callaghan, T.V., M. Johansson, and T.D. Prowse eds. 2011a. Arctic cryosphere: Changes and impacts, ed. T.V. Callaghan, M. Johansson, and T.D. Prowse. Ambio 40(S1). doi:10.1007/ s13280-011-0210-0.

Callaghan, T.V., M. Johansson, R.D. Brown, P.Y. Groisman, N. Labba, and V. Radionov. 2011b. Changing snow cover and its impacts. In Snow, water, ice and permafrost in the Arctic (SWIPA), Chap. 4, pp. 59. Arctic Monitoring and Assessment Programme (AMAP), Oslo.

Callaghan, T.V., M. Johansson, R.D. Brown, P.Y. Groisman, N. Labba, V. Radionov, R.G. Barry, O.N. Bulygina, et al. 2011c. The changing face of Arctic snow cover: A synthesis of observed and projected changes. In Arctic cryosphere-Changes and impacts, ed. T.V. Callaghan, M. Johansson, and T.D. Prowse. Ambio 40(S1). doi:10.1007/s13280-011-0212-y.

Comiso, J. 2003. Warming in the Arctic from clear sky satellite observations. Journal of Climate 16: 3498-3510.

Dickson, R.R., and E. Farhbach. 2010. Observing our Northern Seas during the IPY. Report of the Arctic Ocean Sciences Board and of the IPY Joint Committee, pp. 34.

Eastman, R., and S.G. Warren. 2010. Interannual variations of Arctic cloud types in relation to sea ice. Journal of Climate 23: 4216-4232.

Francis, J.A., W. Chan, D.J. Leathers, J.R. Miller, and D.E. Veron. 2009. Winter Northern Hemisphere weather patterns remember summer Arctic sea ice extent. Geophysical Research Letters 36: L07503. doi:10.1029/2009GL037274. 
Grant, A.N., S. Bronnimann, and L. Haimberger. 2008. Recent Arctic warming vertical structure contested. Nature 455: E2-E3. doi: 10.1038/nature07257.

Graversen, R.G., T. Mauritsen, M. Tjernstrom, E. Kallen, and G. Svensson. 2008. Vertical structure of recent Arctic warming. Nature 451: 53-56.

Hartmann, B., and G. Wendler. 2005. The significance of the 1976 Pacific climate shift in the climatology of Alaska. Journal of Climate 18: 4824-4839.

Holliday, N.P., S.L. Hughes, A. Lavin, K.A. Mork, G. Nolan, W. Walkowski, and A. Bresczynska-Moller. 2007. The end of a trend? The progression of unusually warm and saline water from the eastern North Atlantic into the Arctic Ocean. CLIVAR Exchanges 12: 19-20.

Honda, M., J. Inoue, and S. Yamane. 2009. Influence of low Arctic sea ice minima on anomalously cold Eurasian winters. Geophysical Research Letters 36: L08707. doi:10.1029/2008GL037079.

Jackson, J.M., E.C. Carmack, F.A. McLaughlin, S.E. Allem, and R.G. Ingram. 2010. Identification, characterization and change of the near-surface temperature maximum in the Canada Basin. Journal of Geophysical Research. doi:10.1029/2009JC005265.

Karl, T.R., J.M. Melillo, and T.C. Peterson (ed.). (2009). Global climate change impacts in the United States. US Global Change Research Program. Cambridge, NY: Cambridge University Press.

Kaufman, D.S., D.P. Schneider, N.P. McKay, C.M. Ammann, R.S. Bradley, K.R. Briffa, G.H. Miller, B.L. Otto-Bliesner, J.T. Overpeck, B.M. Vinther, and Arctic Lakes 2K Project Members. 2009. Recent warming reverses long-term arctic cooling. Science 325: 1236. doi:10.1126/science. 1173983.

Kay, J.E., T. L'Ecuyer, A. Gettelman, G. Stephens, and C. O'Dell. 2008. The contribution of cloud and radiation anomalies to the 2007 Arctic sea ice extent minimum. Geophysical Research Letters 35: L08503. doi:10.1029/2008GL033451.

Key, J., C.E. Boggild, M. Sharp, D. Yang, A. Klepikov. 2011. Observational needs and knowledge gaps for the cryosphere. In Snow, water, ice and permafrost in the Arctic (SWIPA), Chap. 11, pp. 9. Arctic Monitoring and Assessment Programme (AMAP), Oslo.

Mantua, N.J., and S.R. Hare. 2002. The Pacific Decadal Oscillation. Journal of Oceanography 58: 35-44.

Meier, W.N., S. Gerland, M.A. Granskog, J.R. Key, C. Haas, G.K. Hovelsrud, K. Kovacs, A. Makshtas, C. Michel, D. Perovich, J.D. Reisr, and B.E.H. van Oort. 2011. Sea ice. In Snow, water, ice and permafrost in the Arctic (SWIPA), Chap. 9, pp. 88. Arctic Monitoring and Assessment Programme (AMAP), Oslo.

Mesquita, M.S., D.E. Atkinson, and K.I. Hodges. 2010. Characteristics and variability of storm tracks in the North Pacific, Bering Sea and Alaska. Journal of Climate 23: 294-311.

Overland, J.E., and M. Wang. 2005. The third Arctic climate pattern: 1930s and early 2000s. Geophysical Research Letters 32: L23808. doi:10.1029/2005GL024254.

Overland, J.E., and M. Wang. 2010. Large-scale atmospheric circulation changes are associated with the recent loss of Arctic sea ice. Tellus 62A: 1-9.

Overland, J.E., M. Wang, and S. Salo. 2008. The recent Arctic warm period. Tellus 60A: 589-597.

Overland, J.E., M. Wang, J.E. Walsh, J.H. Christensen, V.M. Kattsov, and W.L. Chapman. 2011. Climate model projections for the Arctic. In Snow, water, ice and permafrost in the Arctic (SWIPA), Chap. 3. Arctic Monitoring and Assessment Programme (AMAP), Oslo.

Peterson, B.J., R.M. Holmes, J.W. McClelland, C.J. Vorosmarty, R.B. Lammers, A.I. Shiklomanov, I.A. Shiklomanov, and S. Rahmstorf. 2002. Increasing river discharge to the Arctic Ocean. Science 298: 2171. doi:10.1126/science.1077445.

Peterson, B., J. McClelland, M. Holmes, R. Curry, J. Walsh, and K. Aagaard. 2006. Acceleration of the Arctic and subarctic freshwater cycle. Science 313: 1061-1066.
Polyakov, I.V., R. Kwok, and J.E. Walsh. 2011. Recent changes of arctic multiyear sea-ice coverage and the likely causes. Bulletin of the American Meteorological Society 92 (on-line version). doi:10.1175/BAMS-D-11-00070.1.

Roberts, E., N. Nawri, and R.E. Stewart. 2008. On the storms passing over southern Baffin Island during Autumn 2005. Arctic 61: 309-321.

Serreze, M.C., and J.A. Francis. 2006. The arctic amplification debate. Climatic Change 76: 241-264. doi: 1007/s10584-005-9017-y.

Serreze, M.C., A. Barrett, and F. Lo. 2005. Northern high latitude precipitation as depicted by atmospheric reanalyses and satellite retrievals. Monthly Weather Review 133: 3407-3430.

Serreze, M.C., A.P. Barrett, J.C. Stroeve, D.N. Kindig, and M.M. Holland. 2008. The emergence of surface-based Arctic amplification. The Cryosphere Discussions 2: 601-622.

Shimada, K., T. Kamoshida, M. Itoh, S. Nishino, E. Carmack, F. McLaughlin, S. Zimmerman, and A. Proshutinsky. 2006. Pacific Ocean inflow: Influence on catastrophic reduction of sea ice cover in the Arctic Ocean. Geophysical Research Letters 33: L08605. doi:10.1029/2005GL025624.

Smedsrud, L.H., A. Sorteberg, and K. Kloster. 2008. Recent and future changes of the Arctic sea-ice cover. Geophysical Research Letters 35: L20503. doi:10.1029/2008GL034813.

Thompson, D.W.J., and J.M. Wallace. 2000. Annular modes in the extratropical circulation. Part I: Month-to-month variability. Journal of Climate 13: 1000-1016.

Timlin, M.S., and J.E. Walsh. 2007. Historical and projected distributions of daily temperature and pressure in the Arctic. Arctic 60: 389-400.

Vavrus, S., M.M. Holland, and D.A. Bailey. 2010. Changes in Arctic clouds during intervals of rapid sea ice loss. Climate Dynamics 36: 1475-1489. doi:10.1007/s00382-010-0816-0.

Walsh, J.E., I. Shapiro, and T.L. Shy. 2005. On the variability and predictability of daily temperatures in the Arctic. AtmosphereOcean 43: 213-230.

Wang, X., and J.R. Key. 2005. Arctic surface, cloud and radiation properties based on the AVHRR Polar Pathfinder dataset, Part II: Recent trends. Journal of Climate 18: 2575-2593.

Wang, X.L., H. Wan, and V.R. Swail. 2006. Observed changes in cyclone activity in Canada and their relationships to major circulation regimes. Journal of Climate 19: 896-915.

Weatherhead, E., S. Gearheard, and R. Barry. 2010. Changes in weather persistence: Insight from Inuit knowledge. Global Environmental Change 20: 523-528. Amsterdam: Elsevier Ltd.

Wood, K.R., and J.E. Overland. 2009. Early 20th century Arctic warming in retrospect. International Journal of Climatology (online version). doi:10.1002/joc.1973.

Wu, B., J. Wang, and J.E. Walsh. 2006. Dipole Anomaly in the winter Arctic atmosphere and its association with sea ice motion. Journal of Climate 19: 210-225.

Zhang, X., A. Sorteberg, J. Zhang, R. Gerdes, and J. Comiso. 2008. Recent radical shifts in atmospheric circulations and rapid changes in Arctic climate system. Geophysical Research Letters 35: L22701. doi:10.1029/2008GL035607.

\section{AUTHOR BIOGRAPHIES}

John E. Walsh $(\bowtie)$ is a Research Professor at the International Arctic Research Center, University of Alaska, Fairbanks. His research interests include climate of the Polar Regions, Arctic climate change, severe weather, and the relationships between changes in climate and weather.

Address: International Arctic Research Center, University of Alaska,

Fairbanks, AK, USA.

e-mail: jwalsh@iarc.uaf.edu 
James E. Overland is the Leader of the Coastal and Arctic Research Division, Pacific Marine Environmental Laboratory/NOAA, Seattle, Washington. His research interests include climate change, oceanography, fisheries, and changes in the Arctic environment.

Address: Pacific Marine Environmental Laboratory, NOAA, Seattle, WA, USA.

e-mail: James.E.Overland@noaa.gov

Pavel Y. Groisman is a Research Scientist with the Global Climate Applications Division of the National Climatic Data Center/NOAA, Asheville, North Carolina USA. His research interests include climate, data synthesis and analysis, the diagnosis of climate variations, and Arctic climate.

Address: National Climatic Data Center, NOAA, Asheville, NC, USA. e-mail: Pasha.Groisman@noaa.gov
Bruno Rudolf is the head of the Global Precipitation Climatology Centre, Deutscher Wetterdienst, Offenbach, Germany. His research interests include hydrometeorology, particularly precipitation and its measurement. His Center is a leader in the synthesis of data and information on global precipitation.

Address: Global Precipitation Climatology Center, Deutscher Wetterdienst, Offenbach, Germany.

e-mail: Bruno.Rudolf@dwd.de 